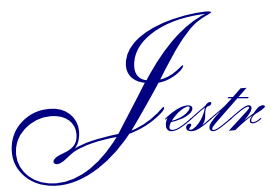

Journal of Engineering Science and Technology Review 11 (3) (2018) 50 - 55

Research Article

www.jestr.org

\title{
Prediction of Nonlinear Dynamic Impact Force History by Finite Element Method
}

\author{
Harun Gokce* \\ TÜBITTAK Defense Industries Research and Development Institute, Ankara, Turkey
}

Received 20 January 2018; Accepted 30 May 2018

\begin{abstract}
This paper presents a new methodology for prediction of nonlinear dynamic impact force by experimental and numerical methods. Conventionally in numerical simulations contact force or reaction force outputs are used for prediction of impact loads, however those are not valid for dynamic cases. Therefore, unlike in literature, load cell is modelled by spring and damper elements. In numerical analyses Johnson-Cook material model is used since it is the most suitable model for impact. To measure the impact force for different velocities, an experimental setup was built. In the experimental setup, adjustable pneumatic piston which is used as an impactor hits a fixed pin and load cell on the piston rod collects the dynamic impact force. Measured impact force is compared with the numerical simulation results. A qualitative agreement was obtained between numerical predictions and the experimental results for the lateral impact conditions. The bending and partial failure of pin during the impact test and also post-test damage photos are compared with the simulation results.
\end{abstract}

Keywords: Impact Mechanics; Johnson-Cook Model; Deformation; FEA; Dynamic Modeling

\section{Introduction}

Identification of impact force for impact events occurring on elastic structures can be performed by various methods that were proposed in the literature [1-2]. To review briefly some of the important contributions in this filed, Wang and Shi have described Johnson-Cook (JC) plasticity and damage model validation using impact experiment. An important parameter in the impact phenomena is the force exerted on the beam by the hammer [2]. This force is of importance, in the design stage for the drivability study of a pile [3], in the dynamic analysis of structures subjected to impact forces and in the dynamic and contact analysis of percussive drilling systems [4].

Yen and $\mathrm{Wu}[5,6]$ have used multiple strain responses along with a mutuality relationship on $2 \mathrm{D}$ plate structures based on Green's functions. It has been successful to find and measure of strain in the force location. Lind et al have modified JC model, which considers the coupled effects of strain, strain rate and deformation temperature, have proposed to describe the tensile behaviors of the studied alloy steel [7]. Results show that the stress-strain values have predicted by the proposed model well agree with experimental ones, which confirmed that the modified JC model can give an accurate and precise estimate of the flow stress for the studied typical high-strength alloy steel. The uniaxial quasi-static and dynamic tensile tests have conducted at different strain rates for 7050-T7451 aluminum alloy [8]. Then, research of the strain rate hardening coefficient in the original JC model at different strains and strain rates have showed that the coefficient is a function of

*E-mail address: harungokce@yahoo.co

ISSN: 1791-2377 @ 2018 Eastern Macedonia and Thrace Institute of Technology. All rights reserved. doi:10.25103/jestr.113.07 strain and strain rate from the tensile experimental results. Furthermore, a modified JC model has been proposed to describe the flow behaviors of the studied alloy based on the correction to the strain rate hardening coefficient. Comparisons between the experimental data and predicted results using the original $\mathrm{JC}$ model and the modified JC model showed that a better agreement can be obtained applying the modified model than the other two models. Shin proposed a technique for identifying the force location using modal displacements and transient signal measured by accelerometers [9]. Vural and Caro have modified the JC model via considering the strong effect of thermal softening on strain-hardening, and proposing a different parameter, in which the enhanced strain-rate sensitivity in dynamic regime has introduced [10]. The comparisons between the experimental results and their predicted results for 2139-T8 aluminum alloy showed that Vural and Caro's modified model has a better prediction for the complex coupling of temperature and rate dependent flow behaviors.

In this study, it was aimed to obtain the dynamic impact force by numerical methods. For this purpose, a test setup was prepared where different velocities and so impact forces could be adjusted. Since JC parameters are widely available in the literature, AI2024-T3 was used instead of an actual design material. As a result of test iterations, velocity and impact force were identified at the most suitable condition for bending behavior. Numerical model has been built according to such identified parameters. The failure of aluminum pin is captured using high-speed photography and compared with that obtained from the numerical simulation. Post-test damage photos and measured impact force from experiment are also compared with the numerical simulation results. Metal deformation under impact loading is a complex dynamic process since it involves high plastic 
strains and large strain rate changes. The JC material model has been widely used to model impact related problems.

\section{Methodology}

The data presented in this paper was collected from a programed of impact testing on pressure vessels carried out at the TÜBİTAK. Discussed in this section is a general description of the test setup, an outline of the design of test specimens and information on the methods of data acquisition employed.

\subsection{Test Setup}

A series of impact tests was carried out on a test setup constructed in the experimental mechanics laboratory at the TÜBİTAK. A pneumatic test setup was designed shown in Figure 1. The tests were used to investigate a number of features of unloading mechanisms on pressure vessel structures. However, summarized in this paper are only the results relating to the measurement of the force propagation velocity.

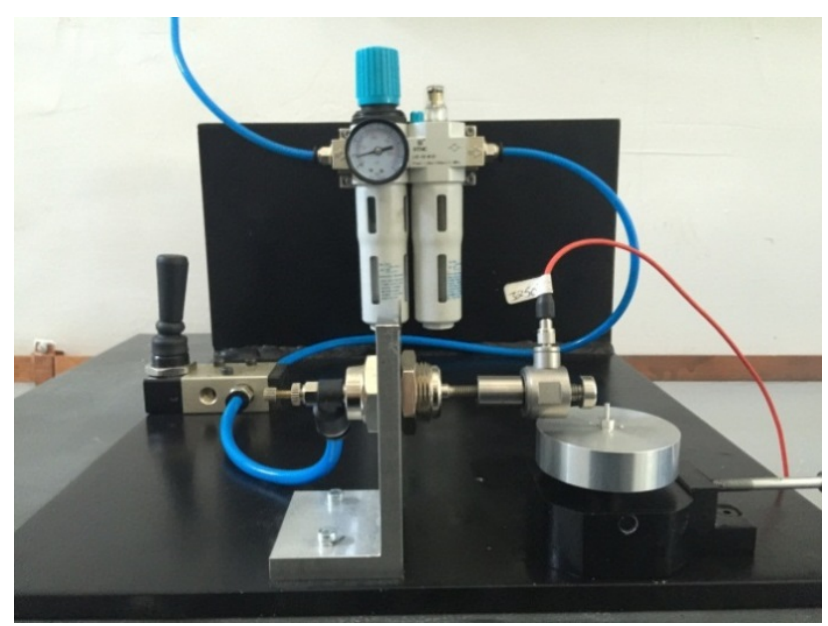

(a)

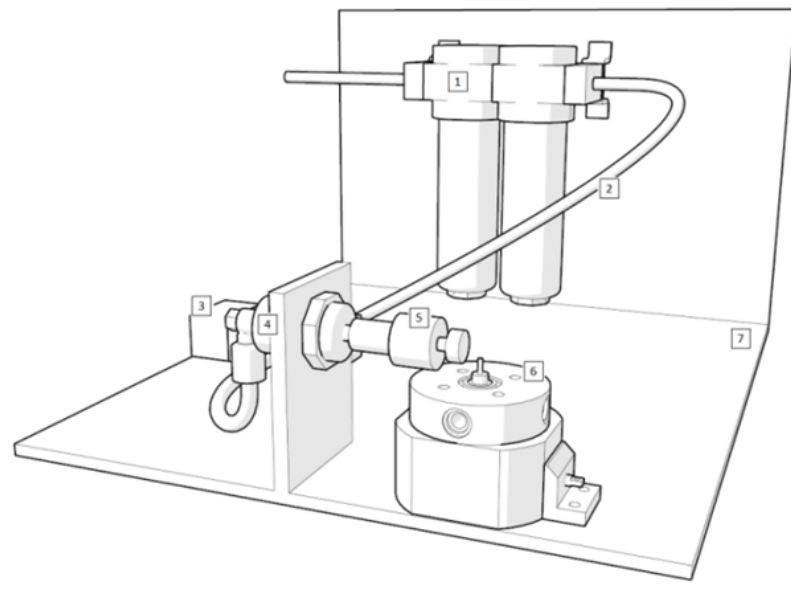

(b)

Fig. 1. Developed experimental setup for impact measurement

\subsection{Data Acquisition Setup}

Pressurized air passing through the conditioner (1) is distributed to the system via a polyurethane pipe with $6 \mathrm{~mm}$ diameter (2). 1/4" hand operated flow control valve (3) was used to control pressure in the setup. In order to obtain the pneumatic impact force required to break the pin, a singleacting and speed-controlled miniature pneumatic cylinder
(4) was placed to the outlet of flow control valve. Load cell (5) was connected to the movable piston of pneumatic cylinder. In order not to make load cell contact directly with the pin and get damaged, a cylindrical part was mounted to front of it. The pin was welded onto the fixture presented by number 6.

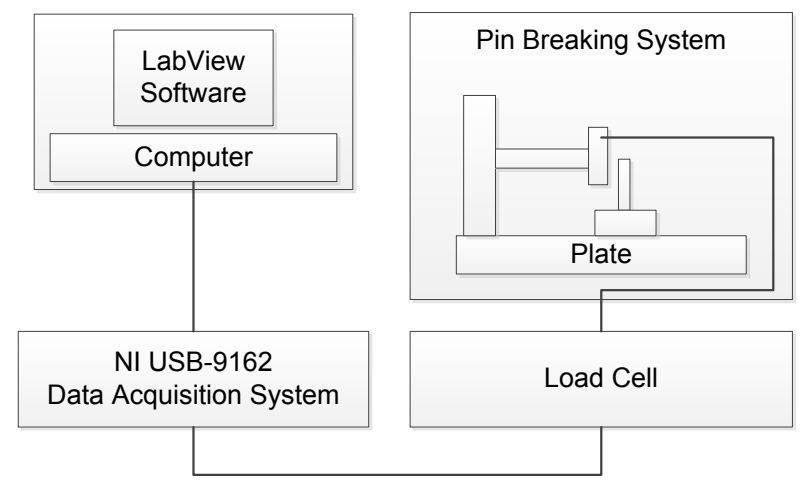

Fig. 2. Schematic Diagram of impact force data acquisition system

Schematic diagram of the impact force measurements and data acquisition system of the pin breaking system is shown in Figure 2. Dytran 1051V6 and National Instruments NI USB 91621 have been used as a load cell and data acquisition system respectively. LabView software has been used for processing data gathered via.

\section{Numerical Simulations}

\subsection{Numerical Model}

The 3D numerical model representing pin breaking test setup was created by Ansa preprocessor, and Abaqus/Explicit was preferred as the solver. The eight-node reduced integration brick hexahedral elements (C3D8R) were used in the simulation. Total number of elements used in the analysis is 400166 . In order to obtain impact force accurately, numerical modelling studies have been done. As a result of those studies, it was recognized that load cell modelling was critical. It was determined from correlation study that load cell should be idealized with spring and damping elements.

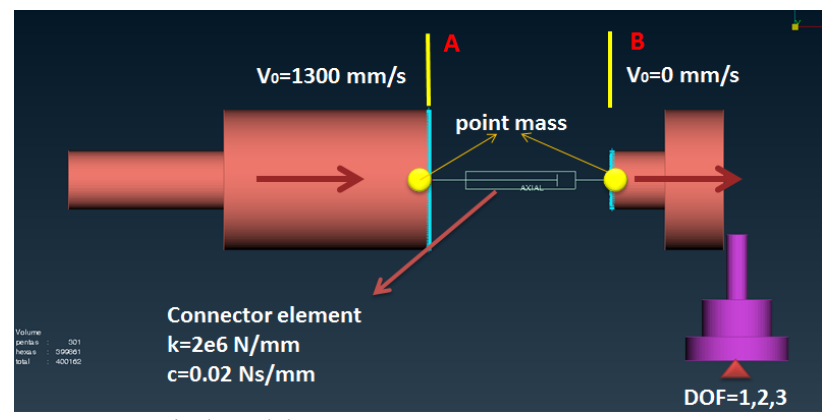

Fig. 3. Numerical Model

Thanks to Abaqus connector element, spring and damping features can be defined out of one single element. In the model as seen in Figure 3, the connector element is connected to the surfaces of solid elements by RBE2 rigid elements. The stiffness value of load cell, which is $2 \times$ 
$\left(10^{6}\right) \mathrm{N} / \mathrm{mm}$, was obtained from product catalogue. Damping value of $\mathrm{c}=0.02 \mathrm{Ns} / \mathrm{mm}$ was entered to the connector element for the stability of the numerical simulation. Total mass of load cell was equally distributed to nodes of the connector element by using point masses. The piston speed which is $1300 \mathrm{~mm} / \mathrm{s}$ was defined to all elements on the left side of A line, however; no initial velocity value was given to the elements on the right side of $\mathrm{B}$ line. According to the scenario in the model, the piston transmits the movement to load cell, and the load cell that operates like a spring transmits the movement to part in front of it and then the collision occurs. The pin was kept as DOF 1-3 from the lower surface of test setup in a way to represent the boundary condition. For the contact algorithm, "Abaqus general contact" was preferred and coefficient of friction was given as 0.12 mesh sensitivity analyses was performed to have optimized mesh for stability, accuracy and computational cost. The results presented in this study are based on this optimized mesh. The average size of the element used in simulation is $0.25 \mathrm{~mm}$.

\subsection{Material Model}

In impact analysis, the material model should include strain rate dependency for both material deformation and failure.

\subsubsection{The Johnson-Cook Plasticity Model}

The Johnson-Cook plasticity model is a particular type of Mises plasticity model with analytical forms of the hardening law and rate dependence; is suitable for highstrain-rate deformation of many materials, including most metals; is typically used in adiabatic transient dynamic simulations. The yield stress is, expressed as [11]

$$
\begin{gathered}
\bar{\sigma}=\left[\mathrm{A}+\mathrm{B}\left(\overline{\bar{\varepsilon}}^{\mathrm{pl}}\right)^{\mathrm{n}}\right]\left[1+\mathrm{Cln}\left(\frac{\dot{\bar{\varepsilon}}^{\mathrm{pl}}}{\dot{\bar{\varepsilon}}_{0}}\right)\right]\left[1-\hat{\theta}^{\mathrm{m}}\right] \\
\hat{\theta}=\left\{\begin{array}{ccc}
0 & \text { for } & \mathrm{T}<\mathrm{T}_{0} \\
\left(\frac{\mathrm{T}-\mathrm{T}_{0}}{\mathrm{~T}_{\mathrm{m}}-\mathrm{T}_{0}}\right) & \text { for } & \mathrm{T}_{0}<\mathrm{T}<\mathrm{T}_{\mathrm{m}} \\
1 & \text { for } & \mathrm{T} \geq \mathrm{T}_{\mathrm{m}}
\end{array}\right\}
\end{gathered}
$$

Where: A is yield stress at ambient temperature, B is hardening modulus, $\mathrm{n}$ is strain hardening exponent, $\mathrm{C}$ is strain rate constant, $\bar{\varepsilon}^{\mathrm{pl}}$ is plastic strain, $\dot{\bar{\varepsilon}}^{\mathrm{pl}}$ is plastic strain rate, $\dot{\bar{\varepsilon}}_{0}$ is reference strain rate, $\mathrm{T}$ is the current temperature, $\mathrm{T}_{\mathrm{m}}$ is the melting temperature, $\mathrm{T}_{0}$ is the reference temperature typically room temperature.

\subsubsection{Johnson - Cook Failure Model}

The Johnson-Cook dynamic failure model is based on the value of the equivalent plastic strain at element integration points; failure is assumed to occur when the damage parameter exceeds 1 . The damage parameter, D, was first presented in Ref [12].

$$
D=\sum \frac{\Delta \bar{\varepsilon}^{p l}}{\bar{\varepsilon}_{f}^{p l}}
$$

Where $\bar{\varepsilon}^{\mathrm{pl}}$ is an increment of the equivalent plastic strain, summation is performed over all increments in the analysis. $\bar{\varepsilon}_{\mathrm{f}}^{\mathrm{pl}}$ is the strain at failure and assumed to be of the form [11].

$\bar{\varepsilon}_{f}^{p l}=\left[d_{1}+d_{2} \exp \left(-d_{3} \frac{p}{q}\right)\right]\left[1+d_{4} \ln \left(\frac{\dot{\varepsilon}^{\mathrm{p} l}}{\dot{\bar{\varepsilon}}_{0}}\right)\right]\left(1+d_{5} \hat{\theta}\right)$
Where $d_{1}-d_{2}$ are material constants to be determined from experiments, $\frac{p}{q}$ is the tri-axial stress, $p$ is the pressure stress; $q$ is the Mises equivalent stress. This expression differs from the original formula published by Johnson and Cook (1985) in the sign of the $d_{3}$ parameter. This difference is motivated by the fact that most materials experience a decrease in $\bar{\varepsilon}_{\mathrm{f}}^{\mathrm{pl}}$ with increasing stress tri-axially; therefore, in the above expression will usually take positive values [17].

\subsubsection{Mie-Gruneisen EOS}

Provide a hydrodynamic material model in which the material's volumetric strength is determined by an equation of state, pressure (positive in compression) is defined as a function of the density and the specific energy.

$p=\frac{\rho_{0} c_{0}^{2} \eta}{(1-s \eta)^{2}}\left[1-\frac{\gamma_{0} \eta}{2}\right]+\gamma_{0} \rho_{0} E_{m}$

$\eta=1-\frac{\rho_{0}}{\rho}$

Where $\eta$ is the nominal volumetric compressive strain, $\rho_{0}$ is the reference density, $c_{0}$ is reference sound speed, $E_{m}$ internal energy per unit mass, $s$ is slope of the $U_{s}-U_{p}$ curve and $\gamma_{0}$ is the Grüneisen ratio [13-16].

\subsubsection{Damage Evolution}

Figure 5 depicts the characteristic stress-strain behavior of a material undergoing damage. In the context of an elasticplastic material with isotropic hardening, the damage manifests itself in two forms: softening of the yield stress and degradation of the elasticity. The solid curve in the figure represents the damaged stress-strain response, while the dashed curve is the response in the absence of damage.

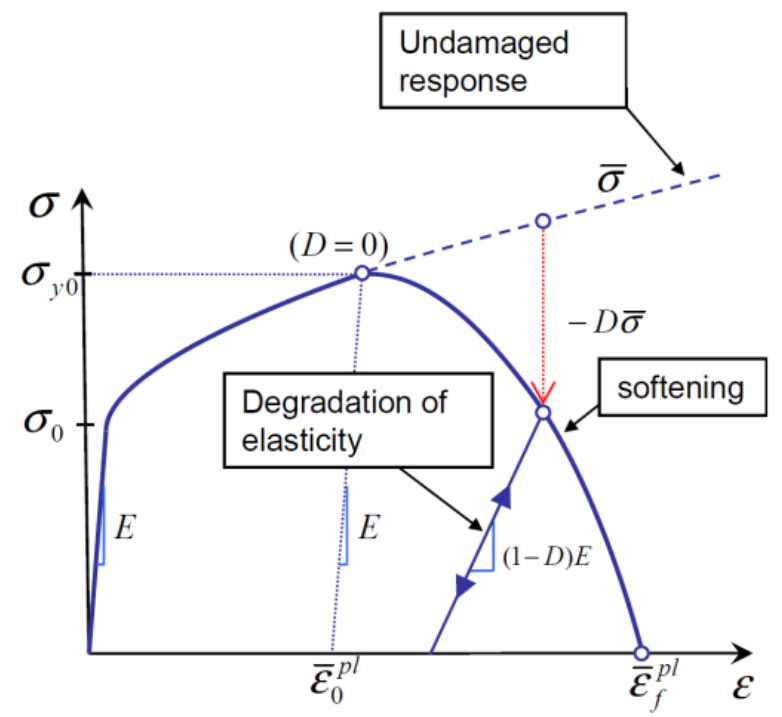

Fig. 4. Stress-strain curve with progressive damage degradation [17].

In the figure $4, \sigma_{\mathrm{y} 0}$ and $\bar{\varepsilon}_{0}^{\mathrm{pl}}$ are the yield stress and equivalent plastic strain at the onset of damage, and $\bar{\varepsilon}_{\mathrm{f}}^{\mathrm{pl}}$ is the equivalent plastic strain at failure; that is, when the overall damage variable reaches the value $\mathrm{D}=1$. The value of the equivalent plastic strain at failure $\bar{\varepsilon}_{\mathrm{f}}^{\mathrm{pl}}$ depends on the characteristic length of the element and cannot be used as a material parameter for the specification of the damage evolution law. The damage evolution law is specified in 
terms of equivalent plastic displacement, $\mathrm{u}^{-\mathrm{pl}}$ or in terms of fracture energy dissipation $\mathrm{G}_{\mathrm{f}}$. The effective plastic displacement was used in this study which is defined with the following evolution equations [18]:

$\overline{\mathrm{u}}_{\mathrm{f}}^{\mathrm{pl}}=\mathrm{L} \bar{\varepsilon}_{\mathrm{f}}^{\mathrm{pl}}$

Where $\mathrm{L}$ is the characteristics length of the element defined in the model as the square root of the integration point area, $\bar{\varepsilon}_{\mathrm{f}}^{\mathrm{pl}}$ is the equivalent plastic strain at complete failure of the material taken form the uni-axial stress strain curve. According to the mesh size used in the numerical model for this test, the value of $\mathrm{L}$ is assumed to be $0.2 \mathrm{~mm}$. Mechanical properties and Johnson-Cook constitutive parameters used in the numerical study are given in Table 1.

Table 1. Mechanical properties and Johnson-Cook constitutive parameters for AI2024-T3 [19,20]

\begin{tabular}{l|c|c}
\hline Parameter & Notation & \\
\hline Density (kg/m3) & $\rho$ & 2785 \\
Young Modulus (GPa) & $\mathrm{E}$ & 74.66 \\
Shear Modulus (GPa) & $\mathrm{G}$ & 28 \\
Poisson Ratio & $v$ & 0.3 \\
Melting Temperature (K) & $T_{m}$ & 911.15 \\
Transition Temperature (K) & $T_{0}$ & 293 \\
Initial Yield Strength (MPa) & $\mathrm{A}$ & 368 \\
Hardening Modulus (MPa) & $\mathrm{B}$ & 683.9 \\
Strain Hardening Exponent & $\mathrm{n}$ & 0.73
\end{tabular}

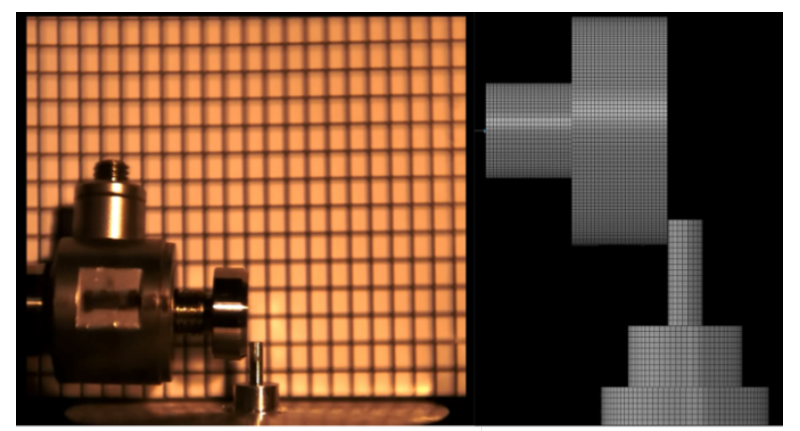

(a)

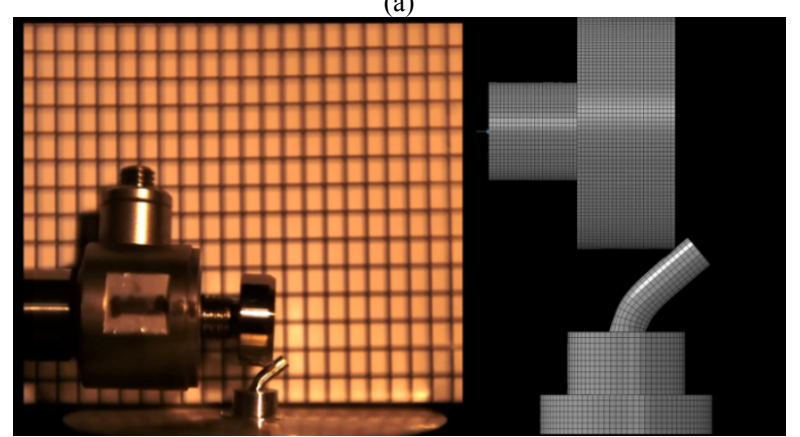

(c)
Thermal Softening Exponent Strain Rate Constant

d1

$\mathrm{d} 2$

d3

d4

d5

Reference Strain Rate (1/s) GRÜNEISEN coefficient reference sound speed $(\mathrm{m} / \mathrm{s})$ Slope of the Us - Up curve
1.7

0.0083

0.112

0.123

1.5

0.007

0

$\dot{\bar{\varepsilon}}_{0}$

$\gamma_{0}$

$\begin{array}{ll}c_{0} & 1900\end{array}$

\begin{tabular}{l|l}
$s$ & 1.338
\end{tabular}

\section{Results and Discussion}

As a result of the performed test iterations, it was decided to adjust miniature pneumatic cylinder velocity to $1300 \mathrm{~mm} / \mathrm{s}$. Speed of pneumatic cylinder was validated via a scaled paper placed at the back of test setup. Same velocity value is applied to the numerical simulation model. The highest value that is read in strain rate tensor in numerical analysis was $12,234 \mathrm{~s}^{-1}$. Captured high-speed photography taken from the test and numerical deflection results were compared side by side as is seen in Figure 5 in the same time intervals. Good agreement in the failure behavior has been observed between experimental and numerical results.

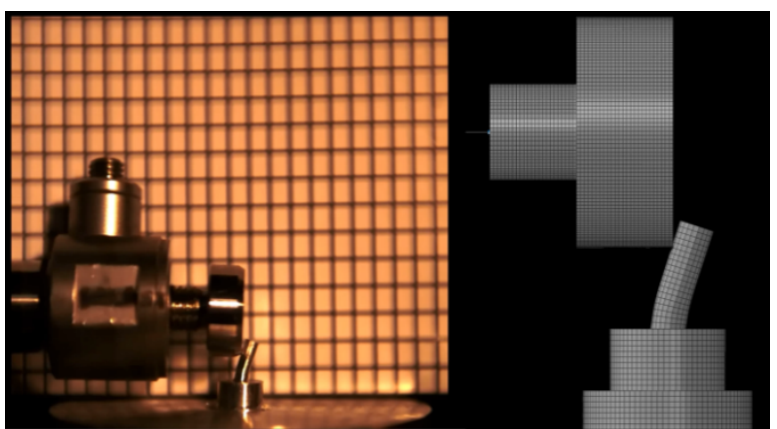

(b)

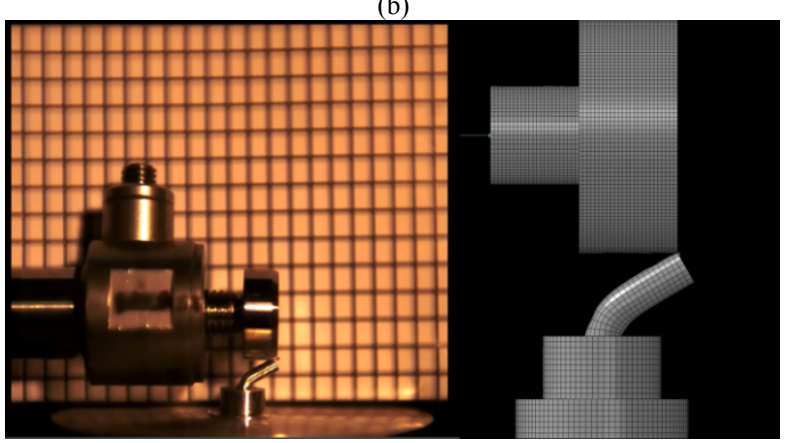

(d)

Fig. 5. Captured high-speed photography versus numerical deflection results during the impact.

As the force data collected from load cell and connector force $(\mathrm{CF})$ obtained from numerical analyses were compared, a difference of $7 \%$ was observed. Statistical values of force results are presented in Table 2.

As the failure behavior of the pin in the numeric simulation result is reviewed, it is observed that damage parameters of the elements on the pin bottom corner which are exposed to compression, reach 1 and so they are removed from the model. When those elements are removed from the model between the time frame (0.0026- 0.0028 $\mathrm{sec}$ ), stiffness of the structure and impact force suddenly drops as seen in Figure 6. It seems that experimental and simulation load distributions are not the same from 0 to 0.0025 time frames. The reason of this, the time elapsed is not sufficient for the pneumatic cylinder to reach its ideal velocity from initial velocity. 
Table 2. Statistical Impact Force Results from experiment and numerical simulation.

\begin{tabular}{c|c|c|c|c}
\cline { 2 - 5 } & $\begin{array}{c}\text { Fmax } \\
(\mathrm{N})\end{array}$ & $\begin{array}{c}\text { Fmin } \\
(\mathrm{N})\end{array}$ & $\begin{array}{c}\text { Fmean } \\
(\mathrm{N})\end{array}$ & $\begin{array}{c}\text { FRMS } \\
(\mathrm{N})\end{array}$ \\
\hline Simulation Result & 10740 & - & 270.3 & 5315 \\
Experimental & 11860 & $\begin{array}{c}10700 \\
-\end{array}$ & -32.8 & 5491 \\
Measurement & & 12390 & & \\
\hline
\end{tabular}

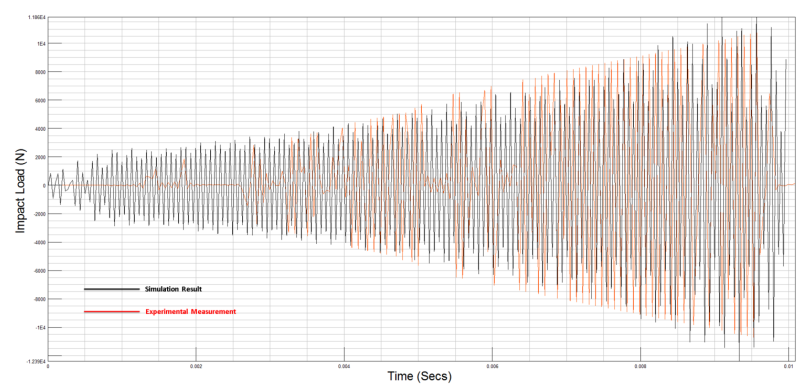

Fig. 6. Simulation result and experimental measurement, load history during the impact

Impact force collected from experiment progresses at very low ranges in certain time frames. The reason of this case is considered as the elastic deformation of test setup due to tolerance based spaces such as between cylinder and piston which cannot be avoided. When post-damage photos of pin after experiment and numerical simulation are compared, a high rate of similarity is observed. In numerical analysis, it was observed that some elements at the tip of the pin are removed from the final geometry; similarly a small amount of scrap was removed from the test sample as seen in Figure 7.

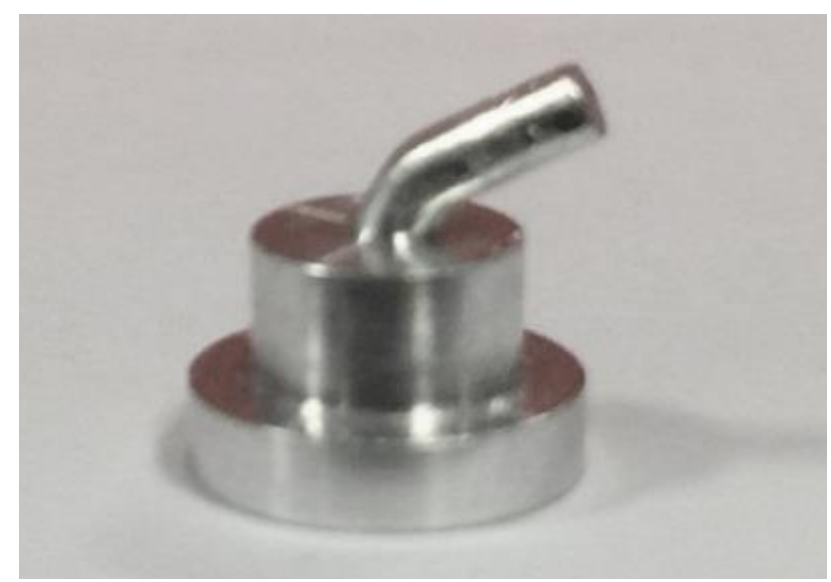

(a)

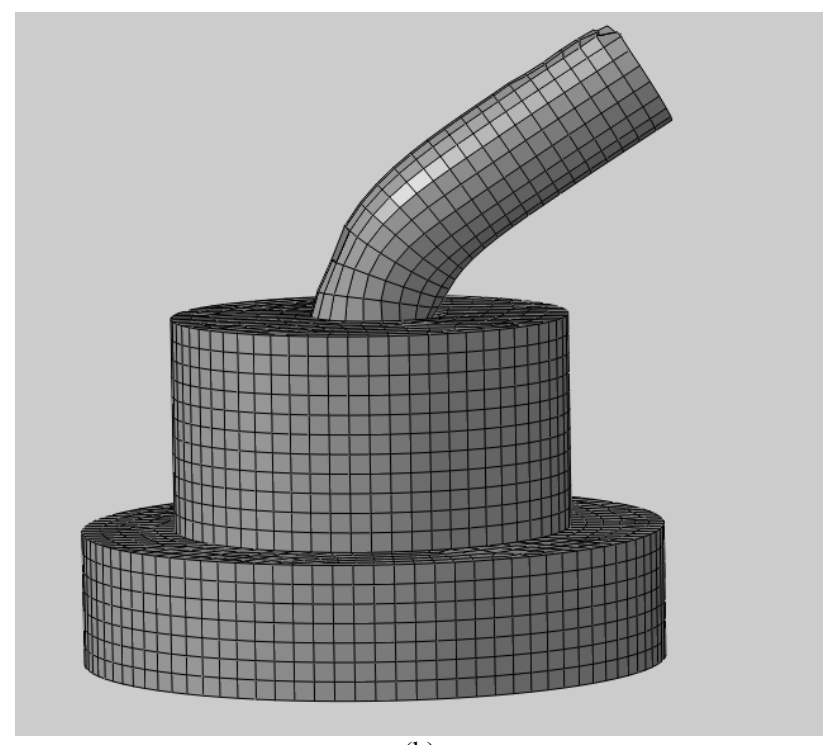

(b)

Fig. 7. Damage photos of specimen after experimental and numerical lateral impact loading

\section{Conclusions}

In the test and analysis comparisons, it was verified that Johnson-Cook constitutive material and damage model could rightly provide bending and partial failure behavior up to $10^{4} \mathrm{~s}^{-1}$ strain rates. In numerical analysis, it was seen that load cell should be idealized with spring and damping elements instead reading of contact force or reaction force for identification of impact force. Thanks to the correlated numerical model, an opportunity was created to analyze pin with different materials and impact parameters in simulation environment.

This is an Open Access article distributed under the terms of the Creative Commons Attribution License

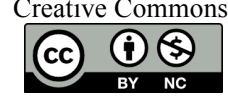

\section{References}

[1] El-Bakari A, Teid J, Abdellatif K, Jacquelin E. "Predictability of Impact Force Localization by Using the Optimization Technique", Procedia Technology, $9^{\text {th }}$ International Conference Interdisciplinary in Engineering, 22:94-100, 2016.

[2] Wang X, Shi J. "Validation of Johnson-Cook plasticity and damage model using impact experiment", International Journal of Impact Engineering, 60:67-75, 2013.

[3] Vershinin VV. "Validation of metal plasticity and fracture models through numerical simulation of high velocity perforation", International Journal of Solids and Structures, 67-68:127-138, 2015.
[4] Martin L. "Numerische Simulation des Betonverhaltens unter Stosswellen mit Hilfe des Elementfreien Galerkin-Verfahrens", Universität Karlsruhe, 2007.

[5] Yen CS, Wu E. "On the Inverse Problem of Rectangular Plates Subjected to Elastic Impact: Method Development and Numerical Verification", Journal of Applied Mechanics, Transactions of the ASME Part: A, 62:692-698, 1995.

[6] Yen CS, Wu E. "On the Inverse Problem of Rectangular Plates Subjected to Elastic Impact: Experimental Verification and further Applications", Journal of Applied Mechanics, Transactions of the ASME Part B, 62:699-705, 1995. 
[7] Lin YC, Chen XM, Liu G. "A modified Johnson-Cook model for tensile behaviors of typical high-strength alloy steel", Materials Science and Engineering Part: A 527:6980-6986, 2010.

[8] Tan JQ, Zhan M, Liu S, Huang T, Guo J, Yang H. "A modified Johnson-Cook model for tensile flow behaviors of 7050-T7451 aluminum alloy at high strain rates", Materials Science \& Engineering Part: A, 631:214-219, 2015.

[9] Shin ES. Real-time recovery of impact force based on finite element analysis. Computers \& Structures, 76:621-627, 2000.

[10] M. Vural, J. Caro, Mater. Sci. Eng. Part: A 520:56-65, 2009.

[11] Johnson GR, Cook W. "Fracture characteristics of three metals subjected to various strains, strain rates, temperatures and pressures", Engineering Fracture Mechanics, 21(1):31-48, 1985.

[12] Johnson GR. "Materials characterization for computations involving severe dynamic loading", Proceeding Army Symposium on Solid Mechanics, 62-67, 1980.

[13] Carroll M, Holt AC. "Suggested Modification of the Model for Porous Materials", Journal of Applied Physics, 43(2):759-761, 1972.
[14] Dobratz BM. "LLNL Explosives Handbook, Properties of Chemical Explosives and Explosive Simulants", California Livermore, 1981.

[15] Herrmann W. "Constitutive Equation for the Dynamic Compaction of Ductile Porous Materials", Journal of Applied Physics, 40(6):2490-2499, 1968.

[16] Lee E, Finger M, Collins W. "JWL Equation of State Coefficients for High Explosives", California Livermore, 1973.

[17] "Abaqus analysis user's manual", Vol 3, V6.11, 2011.

[18] Hillerborg A, Modeer M, Petersson PE. "Analysis of Crack Formation and Crack Growth in Concrete by Means of Fracture Mechanics and Finite Elements", Cement and Concrete Research, 6:773-782, 1976.

[19] Matsagar V. "Advances in Structural Engineering Mechanics", India: Springer Vol: 1, 2015.

[20] Steinberg DJ. "Equation of state and strength properties of selected materials", California Livermore, 1996. 